\title{
Is lactate a volume transmitter of metabolic states of the brain?
}

\section{Linda H. Bergersen ${ }^{1,2,3}$ * and Albert Gjedde $2,3,4,5,6$}

'The Brain and Muscle Energy Group, Centre for Molecular Biology and Neuroscience, Institute for Basic Medical Sciences, University of Oslo, Oslo, Norway

${ }^{2}$ Department of Neuroscience and Pharmacology, University of Copenhagen, Copenhagen, Denmark

${ }^{3}$ Center for Healthy Aging, Faculty of Health Sciences, University of Copenhagen, Copenhagen, Denmark

${ }^{4}$ Center of Functionally Integrative Neuroscience, Aarhus University, Aarhus, Denmark

${ }^{5}$ McConnell Brain Imaging Center, Montreal Neurological Institute, McGill University, Montreal, QC, Canada

${ }^{6}$ Department of Radiology and Radiological Science, Johns Hopkins University, Baltimore, MD, USA

\section{Edited by:}

Sebastian Cerdan, Instituto de Investigaciones Biomedicas

Alberto Sols, Spain

\section{Reviewed by:}

Vladimir Parpura, University of Alabama, USA

Sebastian Cerdan, Instituto de Investigaciones Biomedicas

Alberto Sols, Spain

Anne-Karine Bouzier-Sore,

CNRS/Université Victor Segalen,

France

\section{*Correspondence}

Linda H. Bergersen, The Brain and Muscle Energy Group, Centre for

Molecular Biology and Neuroscience and Institute for Basic Medical

Sciences, University of Oslo, P.O. Box 1105 Blindern, No-0317 Oslo, Norway. e-mail: I.h.bergersen@medisin.uio.no
We present the perspective that lactate is a volume transmitter of cellular signals in brain that acutely and chronically regulate the energy metabolism of large neuronal ensembles. From this perspective, we interpret recent evidence to mean that lactate transmission serves the maintenance of network metabolism by two different mechanisms, one by regulating the formation of CAMP via the lactate receptor GPR81, the other by adjusting the NADH/NAD ${ }^{+}$redox ratios, both linked to the maintenance of brain energy turnover and possibly cerebral blood flow. The role of lactate as mediator of metabolic information rather than metabolic substrate answers a number of questions raised by the controversial oxidativeness of astrocytic metabolism and its contribution to neuronal function.

Keywords: lactate, lactate receptor, central fatigue, metabolic information, volume transmission
Here, we present the perspective that lactate acts as a volume transmitter in brain tissue by distributing cellular signals that are relevant to the metabolic support of large neuronal ensembles. We interpret recent evidence to mean that lactate transmission is involved in the maintenance of network homeostasis by two different mechanisms; one by regulation of neuronal cAMP formation through the lactate receptor GPR81, the other by adjustment of the NADH/NAD ${ }^{+}$redox ratio. Lactate is an intermediary metabolite in brain energy metabolism, the role of which is controversial (Dienel, 2011). Traditionally, lactate was considered a waste product with no certain function in the metabolic housekeeping when eukaryotic cells have sufficient oxygen. However, it is also held to be a "preferred" substrate of energy metabolism, in muscle (Brooks, 2009) as well as in brain (Bouzier-Sore et al., 2003; Smith et al., 2003; Wyss et al., 2011). This alleged preference revives an ancient claim of lactate's service as nutrient for neurons that do not phosphorylate glucose to the extent required by neuronal energy metabolism (Andriezen, 1893; DiNuzzo et al., 2011). A cue to the notion of a signaling role of lactate, irrespective of any role as intermediary metabolite, is the observation that lactate regulates cerebral blood flow (Gordon et al., 2008).

\section{VOLUME TRANSMISSION}

The concept of volume transmission, introduced by Luigi Agnati and Kjell Fuxe in 1986, designates is a form of communication in brain tissue in which modulators act across wide distances when their sites of release and removal are further apart than for "wired" transmission, characteristic of focused synaptic action (Fuxe et al., 2010). Volume transmission affects large volumes of tissue and undergoes change more slowly than wired transmission. The concept of volume transmission in brain therefore overlaps with forms of paracrine and autocrine signaling. The canonical volume transmitters are monoamines, released from varicosities along the fibers of monoaminergic neurons and removed by transporters at sites reached after variable distances of diffusion. However, the list of potential agents of volume transmission is long, as any molecule that engages receptors, transporters, or enzymes far from a place of synthesis or release may qualify as a volume transmitter, including the archetypical wired transmitter glutamate (Okubo and Iino, 2011). Another potential volume transmitter is L-DOPA, which shares with lactate the ability to move across cellular membranes and reach cells far from the sites of generation (Gjedde et al., 1993; Ugrumov, 2009).

\section{LACTATE RECEPTOR GPR81}

The G-protein-coupled 7TM receptor (GPR) family includes members that mediate specific actions of hydroxyl carboxylic acids (HCA), including GPR81, also known as HCA1 receptor (Blad et al., 2011), which serves lactate's downregulation of cAMP, as shown in adipocytes (Ahmed et al., 2009). The GPR81 
is prominent in adipose tissue, where it inhibits lipolysis, but it is known also to be expressed in a wider range of organs such as liver, kidney, skeletal muscle, spleen, and testis (Gantz et al., 1997; Ge et al., 2008; Liu et al., 2009; Rooney and Trayhurn, 2011). Evidence from in situ hybridization show a widespread distribution of GPR81 mRNA in the brain, predominantly in neurons, including the principal neurons in cortex, hippocampus (pyramidal and granule cells), and cerebellum (granule cells), while labeling of astrocytes cannot be excluded (The Allen Institute for Brain Science $^{1}$, GENSTAT ${ }^{2}$, St. Jude Children's Research Hospital ${ }^{3}$ ). The receptor's reported affinities for L-lactate range from 1.3 to $5 \mathrm{mM}$ (Cai etal., 2008; Liu etal., 2009), which is consistent with the range of lactate concentrations measured in brain tissue in vivo (Abi-Saab et al., 2002). The binding of lactate to GPR81 attenuates the formation of CAMP, which in turn inhibits protein kinase A and hence glycogenolysis, leading to decreases of glucose-1phosphate and glucose-6-phosphate (G6P) that affect glycolysis in the cytosol, as recently shown by kinetic modeling (DiNuzzo et al., 2010). The decrease of G6P affects its role as allosteric regulator of hexokinase $(\mathrm{HK})$, including the association of $\mathrm{HK}$ with the voltage dependent anion channel (VDAC) in the outer mitochondrial membrane, with important consequences for the efficiency of oxidative phosphorylation of ADP (Wilson, 2003; Mailloux and Harper, 2011). The main thrust of this perspective is the importance of any physical separation of $\mathrm{HK}$ and pyruvate dehydrogenase $(\mathrm{PDH})$ activities, which would lead to diffusion of lactate between the sites. As such, this concept is not limited to major compartments or cell types but applies equally well to subdivisions of cells, such as distal vs proximal dendrites and astrocytic processes vs cell bodies rather than to astrocyte/neuron differences (Figure 1).

\section{CYTOSOLIC AND MITOCHONDRIAL NADH/NAD+ REDOX RATIOS AND LACTATE DEHYDROGENASES}

Lactic and pyruvic acids interact through the actions of the cytosolic near-equilibrium lactate dehydrogenase (LDH) isozymes, which reflect the cytosolic $\mathrm{NADH} / \mathrm{NAD}^{+}$ratios in cytosol. The cytosolic and the mitochondrial redox states are linked through a network of redox reactions and inner membrane transport processes, but the exact relation between cytosolic and mitochondrial NADH/NAD ${ }^{+}$ratios is not known. There are reports of mitochondrial LDH activity (Brooks, 2009) and therefore potential for coupling of lactate-pyruvate and $\mathrm{NADH} / \mathrm{NAD}^{+}$ratios in the mitochondrial matrix. Changes of the $\mathrm{NADH} / \mathrm{NAD}^{+}$redox ratios trigger several intracellular responses, including expression of genes by modification of histone deacetylases, which profoundly affect the regulation of protein synthesis. For example sirtuins, gene-regulating histone deacetylases with effects on regulation of caloric intake, metabolism and age-related diseases (Finkel et al., 2009), are tightly redox regulated through the $\mathrm{NADH} / \mathrm{NAD}^{+}$ratio (Gambini et al., 2011). Genes activated by lactate through lactate-sensitive response elements include c-fos, c-jun, c-ets, Hyal-1, Hyal-2, CD44, and caveolin-1 (Formby and

${ }^{1}$ http://www.brain-map.org

${ }^{2}$ http://www.ncbi.nlm.nih.gov/gensat

${ }^{3}$ http://www.stjudebgem.org

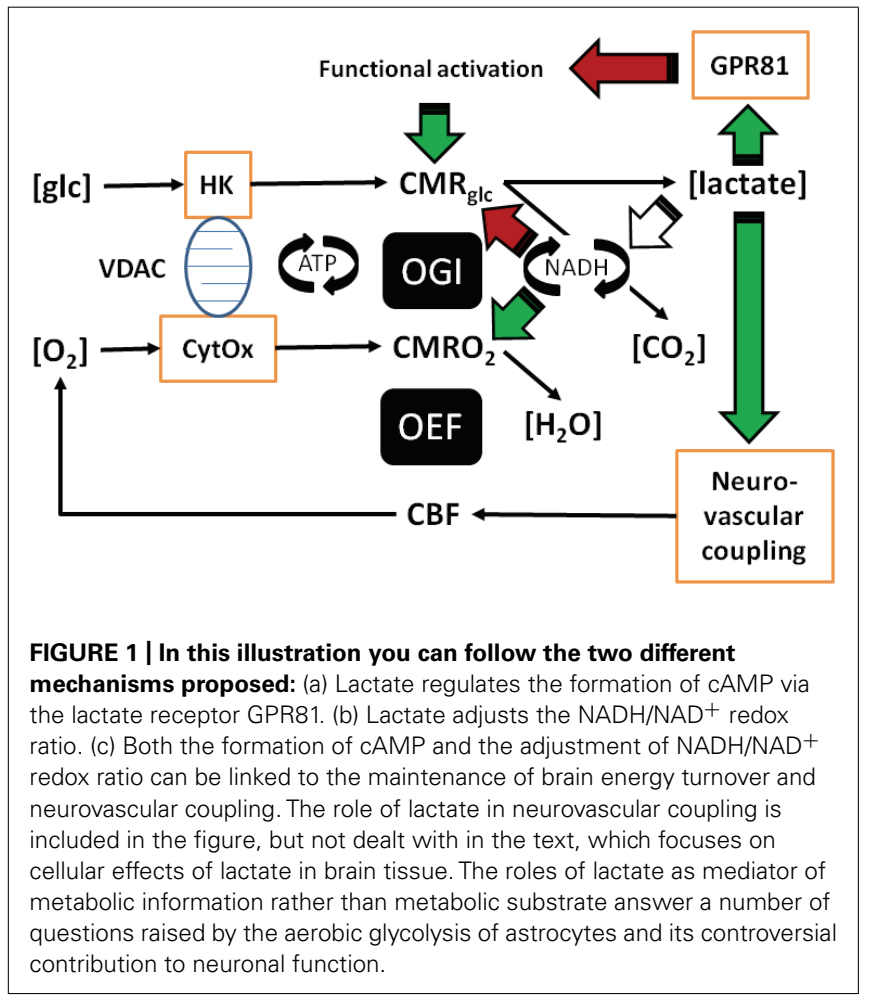

Stern, 2003). The DNA binding of the transcription factor fosjun heterodimer AP-1 depends on a specific cysteine residue being in the reduced sate (Abate etal., 1990), acting as a redox sensor. In addition, pyruvate, which interacts closely with lactate as dictated by the $\mathrm{NADH} / \mathrm{NAD}^{+}$ratio, is a gene regulator through histone deacetylase inhibition (Thangaraju et al., 2009; Rajendran et al., 2011).

\section{NEAR-EQUILIBRIUM REACTIONS AND LACK OF COMPARTMENTATION}

Both the LDH isozymes and the monocarboxylic acid transporters (MCT) of the blood-brain barrier and cell membranes of brain tissue mediate near-equilibrium transfer of lactate (Bergersen et al., 2001; Bergersen, 2007) when unidirectional fluxes exceed net fluxes by several orders of magnitude. Therefore LDH and MCT proteins serve to dissipate lactate concentration differences across cell membranes and tissue volumes. Thus, changes of pyruvate and lactate concentrations in one place lead to similar changes of lactate concentrations across large volumes of brain tissue over long times. In turn, any effects of changes of lactate on the NADH/NAD ${ }^{+}$ratio in one place lead to similar effects in widely distributed populations of cells (cf. Cerdán et al., 2006; Ramírez et al., 2007; Rodrigues et al., 2009). In fact, the transfer of lactate is so efficient that it is difficult to observe any differences of lactate concentrations across cell membranes in brain tissue (Gjedde and Marrett, 2001; Ido et al., 2001, 2004; Gjedde et al., 2002), such that significant cellular compartmentation of lactate is unlikely to exist under normal conditions, except briefly. The high concentration of MCT2 at the PSD of fast excitatory synapses co-localized with glutamate receptors (Bergersen et al., 
2001, 2005) suggests a particular need for lactate transfer at these synapses perhaps involved in volume transmission signaling. In addition to moving through brain tissue by facilitated transfer across plasma membranes of all cells through MCT1, MCT2, and MCT4, and by diffusion through the extracellular space, lactate spreads through the astroglial network in which individual astrocytes are connected by gap junctions (Dienel, 2011; Mathiesen et al., 2011). One puzzle is the kinetic differences among the isozymes of $\mathrm{LDH}$ (O'Brien et al., 2007), the physiological role of which at near-equilibrium is not yet understood (Ross et al., 2010; Quistorff and Grunnet, 2011; Ross, 2011), but may be related to the proposed function of lactate as a volume transmitter in cytosolic and perhaps mitochondrial environments with widely differing $\mathrm{NADH} / \mathrm{NAD}^{+}$ratios (Figure 1).

\section{NON-STEADY-STATES AND ACTIVATION}

The purported changes of lactate concentrations and the consequent redistribution of lactate happen whenever and wherever sites of generation and metabolic conversion of pyruvate are unmatched or physically separated. Pyruvate is the main end product of aerobic glycolysis, which is controlled by the concerted action of the HK and phosphofructokinase (PFK) enzyme complex, while the fate of pyruvate is determined by the $\mathrm{PDH}$ complex in mitochondria. The two enzyme complexes are the main flux-generating determinants of brain energy metabolism as controlled by allosteric effectors, and both therefore define the path that is open to the respective so-called "pathway substrates," glucose in the case of the HK-PFK complex, pyruvate in the case of the PDH complex (Gjedde, 2007). The temporal and spatial integration of the activities of these enzyme complexes is then the key to the dynamics of lactate inside and among the cells of brain tissue. Both the oxygen-glucose index (OGI) and the oxygen extraction fraction (OEF) decline during the temporary departures from steady-state associated with functional activation of brain regions, attributed to increased aerobic glycolysis (Madsen et al., 1999; Schmalbruch et al., 2002). The declines are signs of focal disintegration of the HK-PFK and PDH activities, resulting in increased lactate-pyruvate ratios, redistribution of lactate and adjustment of $\mathrm{NADH} / \mathrm{NAD}^{+}$ratios within the sphere of action of the redistributed lactate. This process seems to be so efficient that it leaves no oxygen deficit or abnormal ATP, ADP, or AMP levels, even in seizures (Larach et al., 2011).

Extracellular lactate concentrations increase during neuronal and synaptic activation in vivo, as determined by microdialysis (Uehara et al., 2008; Bero et al., 2011), and proton magnetic resonance spectroscopy minutes after stimulation (Prichard et al., 1991; Sappey-Marinier et al., 1992; Maddock et al., 2006), following a transient decrease $5 \mathrm{~s}$ after stimulation (Mangia et al., 2003). These observations are consistent with adjustments that follow the perturbation of an existing steady-state and the subsequent return to a potential new steady-state, depending on conditions, such as the intensity of the continuing neuronal activation. The lactate dynamics are uniquely dependent on the shifts among these steady- and non-steady-states of brain energy metabolism. The observations that the OGI declines during the non-steadystate of the early stages of functional brain activation, signifies increased lactate production in the tissue as a whole, evidently due to increased glucose consumption relative to oxygen consumption. The observations are consistent with changes of glucose consumption that match the changes of blood flow during activation, while changes of oxygen consumption generally do not (Gjedde et al., 2002; Paulson et al., 2010). Recent evidence also shows that the changes of glucose consumption exceed the changes of oxygen consumption at specific regional locations (Vaishnavi et al., 2010), rather than everywhere, creating the gradients of lactate concentration that serve to redistribute lactate inside as well as outside cells and across the blood-brain barrier. The regional variation of the OGI (Vaishnavi et al., 2010) may possibly be related to different ratios of cell types (low in cortex with numerous astrocytes, high in cerebellum with numerous neurons). Any separation of the sites of lactate generation and lactate metabolism inside or among cells therefore must result in shuttling of lactate among its sites of generation and metabolism. The fluxes alter the interactions with enzymes and transporters that qualify as volume transmission. Thus, the temporal and spatial mismatches of lactate generation and metabolism arise because different cellular and subcellular compartments react differently to activating stimuli (Gjedde et al., 2005; Vaishnavi et al., 2010).

\section{CENTRAL vs PERIPHERAL FATIGUE}

Physical exertion generates considerable increases of lactate concentration in the circulation. It has been shown by MR spectroscopy that blood lactate is an efficient substrate for the brain, and especially for neurons, both in rat (Bouzier et al., 2000; Hassel and Bråthe, 2000) and in humans (Boumezbeur et al., 2010). The increased lactate also has effects on brain metabolism, which are characterized by reduction of the cerebral OGI in the context of a state known as "central fatigue" (Dalsgaard, 2006; Dalsgaard and Secher, 2007; Rasmussen et al., 2010). Central fatigue precedes the muscle fatigue that also relates to increased lactate (van Hall, 2010). The mechanism responsible for the onset of central fatigue is not known with certainty but appears to be related to decreased oxygen delivery, which in turn may be due to increased lactate in brain tissue and possible effects on lactate's receptor GPR81 (Rasmussen etal., 2010; Gam et al., 2011). The downregulation of cAMP formation by binding of lactate to GPR81 offers a novel explanation of central fatigue and "over-training" distress (Lehmann et al., 1993), and possibly in part the asthenia seen in advanced cancer, a condition that is known to be characterized by chronically increased blood lactate levels (Koppenol et al., 2011). Chronically increased lactate levels similarly are held to be characteristic of old age and dementia, based on the properties of a mtDNA mutator mouse model (Ross et al., 2010). These effects contrast with the upregulation of cAMP by noradrenaline with effects such as arousal and enhanced brain performance (Berridge, 2008).

Many other observed effects of lactate on neuronal function may result from enzyme- or receptor-mediated responses rather than from the direct actions of lactate as a metabolic substrate. For example, the observation that lactate administration protects against ischemia (Schurr et al., 1997, 2001; Cureton et al., 2010) has been ascribed to enhanced neuronal energy turnover. However, this is not readily explained by metabolic effects, as lactate metabolism cannot raise energy turnover under ischemic 
conditions, although after ischemia and in the penumbra of vascular occlusion, the availability of lactate for oxidation may assist in alleviating ischemia induced damage (Schurr et al., 2001; Berthet et al., 2009). Similarly, the observed protective effect of lactate on glutamate toxicity in the brain (Ros et al., 2001) may be due to receptor-mediated inhibition, rather than the simple satisfaction of the metabolic demands of neurons exposed to high concentrations of glutamate (Schurr et al., 1999). In microdialysis of the cerebral cortex, excitotoxic concentrations of glutamate raised lactate at the expense of glucose in the dialysate. The addition of L-lactate caused the lesion to become smaller and abolished the decrease of glucose. Replacing L-lactate with the non-physiological D-lactate isomer expanded the lesion and raised L-lactate in the dialysate above the level observed with glutamate alone (Ros et al., 2001), consistent with the claim that endogenously produced lactate is neuroprotective by means of receptor interaction.

The suppression of noradrenalin and adrenalin releases by blood lactate clamps at $4 \mathrm{mM}$ (Fattor et al., 2005) also suggests a receptor mechanism, consistent with the postulated reduction of cAMP formation by GRP81 activation. Interestingly, also $\beta$-adrenoceptor blockers, which presumably act by reducing intracellular cAMP, are neuroprotective in stroke and other brain

\section{REFERENCES}

Abate, C., Patel, L., Rauscher, F. J., and Curran, T. (1990). Redox regulation of fos and jun DNA-binding activity in vitro. Science 249, 1157-1161.

Abi-Saab, W. M., Maggs, D. G., Jones, T., Jacob, R., Srihari, V., Thompson, J., Kerr, D., Leone, P., Krystal, J. H., Spencer, D. D., During, M. J., and Sherwin, R. S. (2002). Striking differences in glucose and lactate levels between brain extracellular fluid and plasma in conscious human subjects: effects of hyperglycemia and hypoglycemia. J. Cereb. Blood Flow Metab. 22, 271-279.

Ahmed, K., Tunaru, S., and Offermanns, S. (2009). GPR109A, GPR109B and GPR81, a family of hydroxycarboxylic acid receptors. Trends Pharmacol. Sci. 30, 557-562.

Andriezen, W. L. (1893). The neuroglia elements in the human brain. $B r$. Med. J. 29, 227-230.

Bergersen, L. H. (2007). Is lactate food for neurons? Comparison of monocarboxylate transporter subtypes in brain and muscle. Neuroscience 145, 11-19.

Bergersen, L., Waerhaug, O., Helm, J., Thomas, M., Laake, p., Davies, A. J., Wilson, M. C., Halestrap, A. P., and Ottersen, O. P. (2001). A novel postsynaptic density protein: the monocarboxylate transporter MCT2 is colocalized with delta-glutamate receptors in postsynaptic densities of parallel fiber-Purkinje cell synapses. Exp. Brain Res. 136, 523-534.
Bergersen, L. H., Magistretti, P. J., and Pellerin, L. (2005). Selective postsynaptic co-localization of MCT2 with AMPA receptor GluR2/3 subunits at excitatory synapses exhibiting AMPA receptor trafficking. Cereb. Cortex 15 , 361-370.

Bero, A. W., Yan, P., Roh, J. H., Cirrito, J. R., Stewart, F. R., Raichle, M. E., Lee, J. M., and Holtzman, D. M. (2011). Neuronal activity regulates the regional vulnerability to amyloid- $\beta$ deposition. Nat. Neurosci. 14, 750-756.

Berridge, C. W. (2008). Noradrenergic modulation of arousal. Brain Res. Rev. 58, 1-17.

Berthet, C., Lei, H., Thevenet, J., Gruetter, R., Magistretti, P. J., and Hirt, L. (2009). Neuroprotective role of lactate after cerebral ischemia. J. Cereb. Blood Flow Metab. 29, 1780-1789.

Blad, C. C., Ahmed, K., Ijzerman, A. P., and Offermanns, S. (2011). Biological and pharmacological roles of HCA receptors. Adv. Pharmacol 62, 219-250.

Boumezbeur, F., Mason, G. F., de Graaf, R. A., Behar, K. L., Cline, G. W., Shulman, G. I., Rothman, D. L., and Petersen, K. F. (2010). Altered brain mitochondrial metabolism in healthy aging as assessed by in vivo magnetic resonance spectroscopy. J. Cereb. Blood Flow Metab. 30, 211-221.

Bouzier, A. K., Thiaudiere, E., Biran, Merle, M. (2000). The metabolism M., Rouland, R., Canioni, P., and

injuries, and also lower extracellular glutamate levels, which may further limit excitotoxic cell damage (Goyagi et al., 2011).

\section{CONCLUSION}

The proposed role of lactate as a mediator of information on changing $\mathrm{NADH} / \mathrm{NAD}^{+}$ratios among the cells of brain tissue has implications for the understanding of regulation of brain energy metabolism, including the communication between cytosol and mitochondria in large populations of cells (Xu et al., 2007). Lactate's inhibition of cAMP formation through G-protein-coupled receptors may be a factor in the development of central fatigue. An action of lactate may therefore be to "smooth" the non-steadystates that underlie the mismatches of glycolysis and oxidative phosphorylation, induced by needs for aerobic glycolysis that satisfy the short time constants of ATP turnover required for maintenance of rapid de- and repolarizations. The redistribution of lactate by the volume transmission is both temporal and spatial and potentially reaches large volumes of tissue, aided by the extended syncytium of astrocytic networks connected by gap junctions. The role of lactate as informant of metabolic states rather than substrate of metabolism solves a number of puzzles that contribute to the controversy surrounding the understanding of astrocytic metabolism and its contribution to neuronal function.

of [3-(13)C]lactate in the rat brain is specific of a pyruvate carboxylasedeprived compartment. J. Neurochem. $75,480-486$.

Bouzier-Sore, A. K., Serres, S., Canioni, P., and Merle, M. (2003). Lactate involvement in neuron-glia metabolic interaction: (13)C-NMR spectroscopy contribution. Biochimie $85,841-848$.

Brooks, G. A. (2009). Cell-cell and intracellular lactate shuttles. J. Physiol. 587, 5591-5600.

Cai, T. Q., Ren, N., Jin, L., Cheng, K., Kash, S., Chen, R., Wright, S. D., Taggart, A. K., and Waters, M. G. (2008). Role of GPR81 in lactatemediated reduction of adipose lipolysis. Biochem. Biophys. Res. Commun. 377, 987-991.

Cerdán, S., Rodrigues, T. B., Sierra, A., Benito, M., Fonseca, L. L., Fonseca, C. P., and García-Martín, M. L. (2006). The redox switch/redox coupling hypothesis. Neurochem. Int. 48, 523-530.

Cureton, E. L., Kwan, R. O., Dozier, K. C., Sadjadi, J., Pal, J. D., and Victorino, G. P. (2010). A different view of lactate in trauma patients: protecting the injured brain. J. Surg. Res. 159, 468-473.

Dalsgaard, M. K. (2006). Fuelling cerebral activity in exercising man. J. Cereb. Blood Flow Metab. 26, 731-750.

Dalsgaard, M. K., and Secher, N. H. (2007). The brain at work: a cerebral metabolic manifestation of central fatigue? J. Neurosci. Res. 85, 33343339.

Dienel, G. A. (2011). Brain lactate metabolism: the discoveries and the controversies. J. Cereb. Blood Flow Metab. doi: 10.1038/jcbfm.2011.175 [Epub ahead of print].

DiNuzzo, M., Gili, T., Maraviglia, B., and Giove, F. (2011). Modeling the contribution of neuronastrocyte cross talk to slow blood oxygenation level-dependent signal oscillations. J. Neurophysiol. 106, 3010-3018.

DiNuzzo, M., Mangia, S., Maraviglia, B., and Giove, F. (2010). Glycogenolysis in astrocytes supports blood-borne glucose channeling not glycogenderived lactate shuttling to neurons: evidence from mathematical modeling. J. Cereb. Blood Flow Metab. 1895-1904.

Fattor, J. A., Miller, B. F., Jacobs, K. A., and Brooks, G. A. (2005). Catecholamine response is attenuated during moderate-intensity exercise in response to the "lactate clamp". Am. J. Physiol. Endocrinol. Metab. 288, 143-147.

Finkel, T., Deng, C. X., and Mostoslavsky, R. (2009). Recent progress in the biology and physiology of sirtuins. Nature 460, 587-591.

Formby, B., and Stern, R. (2003). Lactate-sensitive response elements in genes involved in hyaluronan catabolism. Biochem. Biophys. Res. Commun. 305, 203-208. 
Fuxe, K., Dahlström, A. B., Jonsson, G., Marcellino, D., Guescini, M., Dam, M., Manger, P., and Agnati, L. (2010). The discovery of central monoamine neurons gave volume transmission to the wired brain. Prog. Neurobiol. 90, 82-100.

Gam, C. M. B., Nielsen, H. B., Secher, N. H., Larsen, F. S., Ott, P., and Quistorff, B. (2011). In cirrhotic patients reduced muscle strength is unrelated to muscle capacity for ATP turnover suggesting a central limitation. Clin. Physiol. Funct. Imaging 31, 169-174.

Gambini, J., Gomez-Cabrera, M. C., Borras, C., Valles, S. L., LopezGrueso, R., Martinez-Bello, V. E., Herranz, D., Pallardo, F. V., Tresguerres, J. A., Serrano, M., and Viña, J. (2011). Free $[\mathrm{NADH}] /[\mathrm{NAD}(+)]$ regulates sirtuin expression. Arch. Biochem. Biophys. 512, 24-29.

Gantz, I., Muraoka, A., Yang, Y. K., Samuelson, L. C., Zimmerman, E. M., Cook, H., and Yamada, T. (1997). Cloning and chromosomal localization of a gene (GPR18) encoding a novel seven transmembrane receptor highly expressed in spleen and testis. Genomics 42, 462-466.

Ge, H., Weiszmann, J., Reagan, J. D., Gupte, J., Baribault, H., Gyuris, T., Chen, J., Tian, H., and Li, Y. (2008). Elucidation of signaling and functional activities of an orphan GPCR, GPR81. J. Lipid Res. 49, 797-803.

Gjedde, A. (2007). "Coupling of brain function to metabolism: evaluation of energy requirements (Chapter 4.4)," in Handbook of Neurochemistry: Brain Energetics from Genes to Metabolites to Cells: Integration of Molecular and Cellular Processes, 3rd Edn, eds A. Lajtha, G. Gibson, and G. Dienel (Heidelberg/New York: Springer Verlag), 400p, 40 illus.

Gjedde, A., Johannsen, P., Cold, J. E., and Østergaard, L. (2005). Cerebral metabolic response to low blood flow: possible role of cytochrome oxidase inhibition. J. Cereb. Blood Flow Metab. 25, 1083-1096.

Gjedde, A., Léger, G. C., Cumming, P., Yasuhara, Y., Evans, A. C., Guttman, M., and Kuwabara, H. (1993). Striatal L-DOPA decarboxylase activity in Parkinson's disease in vivo: implications for the regulation of dopamine synthesis. J. Neurochem. 61 , 1538-1541.

Gjedde, A., and Marrett, S. (2001). Glycolysis in neurons, not astrocytes, delays oxidative metabolism of human visual cortex during sustained checkerboard stimulation in vivo. J. Cereb. Blood Flow Metab. 21, 1384-1392.
Gjedde, A., Marrett, S., and Vafaee, M. (2002). Oxidative and nonoxidative metabolism of excited neurons and astrocytes. J. Cereb. Blood Flow Metab. 22, 1-14.

Gordon, G. R., Choi, H. B., Rungta, R. L., Ellis-Davies, G. C., and MacVicar, B. A. (2008). Brain metabolism dictates the polarity of astrocyte control over arterioles. Nature 456, 745-749.

Goyagi, T., Nishikawa, T., and Tobe, Y. (2011). Neuroprotective effects and suppression of ischemiainduced glutamate elevation by $\beta 1$ adrenoreceptor antagonists administered before transient focal ischemia in rats. J. Neurosurg. Anesthesiol. 23, 131-137.

Hassel, B., and Bråthe, A. (2000). Cerebral metabolism of lactate in vivo: evidence for neuronal pyruvate carboxylation. J. Cereb. Blood Flow Metab. 20, 327-336.

Ido, Y., Chang, K., and Williamson, J. R. (2004). NADH augments blood flow in physiologically activated retina and visual cortex. Proc. Natl. Acad. Sci. U.S.A. 101, 653-658.

Ido, Y., Chang, K., Woolsey, T. A., and Williamson, J. R. (2001). NADH: sensor of blood flow need in brain, muscle, and other tissues. FASEB J. 15, 1419-1421.

Koppenol, W. H., Bounds, P. L., and Dang, C. V. (2011). Otto Warburg's contributions to current concepts of cancer metabolism. Nat. Rev. Cancer 11, 325-337.

Larach, D. B., Kofke, W. A., and Le Roux, P. (2011). Potential non-hypoxic/ischemic causes of increased cerebral interstitial fluid lactate/pyruvate ratio: a review of available literature. Neurocrit. Care 15, 609-622.

Lehmann, M., Foster, C., and Keul, J. (1993). Overtraining in endurance athletes: a brief review. Med. Sci. Sports Exerc. 25, 854-862.

Liu, C., Wu, J., Zhu, J., Kuei, C., Yu, J., Shelton, J., Sutton, S. W., Li, X., Yun, S. J., Mirzadegan, T., Mazur, C., Kamme, F., and Lovenberg, T. W. (2009). Lactate inhibits lipolysis in fat cells through activation of an orphan G-protein-coupled receptor, GPR81. J. Biol. Chem. 284, 2811-2822.

Maddock, R. J., Buonocore, M. H., Lavoie, S. P., Copeland, L. E., Kile, S. J., Richards, A. L., and Ryan, J. M. (2006). Brain lactate responses during visual stimulation in fasting and hyperglycemic subjects: a proton magnetic resonance spectroscopy study at 1.5 Tesla. Psychiatry Res. 148, 47-54.

Madsen, P. L., Cruz, N. F., Sokoloff, L., and Dienel, G. A. (1999). Cerebral oxygen/glucose ratio is low during sensory stimulation and rises above normal during recovery: excess glucose consumption during stimulation is not accounted for by lactate efflux from or accumulation in brain tissue. J. Cereb. Blood Flow Metab. 19, 393-400.

Mailloux, R. J., and Harper, M. E. (2011). Uncoupling proteins and the control of mitochondrial reactive oxygen species production. Free Radic. Biol. Med. 51, 1106-1115.

Mangia, S., Garreffa, G., Bianciardi, M. Giove, F., Di Salle, F., and Maraviglia, B. (2003). The aerobic brain: lactate decrease at the onset of neural activity. Neuroscience 118, 7-10.

Mathiesen, C., Caesar, K., Thomsen, K., Hoogland, T. M., Witgen, B. M., Brazhe, A., and Lauritzen, M. (2011). Activity-dependent increases in local oxygen consumption correlate with postsynaptic currents in the mouse cerebellum in vivo. J. Neurosci. 31, 18327-18337.

O’Brien, J., Kla, K. M., Hopkins, I. B., Malecki, E. A., and McKenna, M. C. (2007). Kinetic parameters and lactate dehydrogenase isozyme activities support possible lactate utilization by neurons. Neurochem. Res. 32 , 597-607.

Okubo, Y., and Iino, M. (2011). Visualization of glutamate as a volume transmitter. J. Physiol. 589, 481-488.

Paulson, O. B., Hasselbalch, S. G., Rostrup, E., Knudsen, G. M., and Pelligrino, D. (2010). Cerebral blood flow response to functional activation $J$. Cereb. Blood Flow Metab. 30, 2-14.

Prichard, J., Rothman, D., Novotny, E., Petroff, O., Kuwabara, T., Avison, M., Howseman, A., Hanstock, C., and Shulman, R. (1991). Lactate rise detected by $1 \mathrm{H}$ NMR in human visual cortex during physiologic stimulation. Proc. Natl. Acad. Sci. U.S.A. 88, 5829-5831.

Quistorff, B., and Grunnet, N. (2011). The isoenzyme pattern of $\mathrm{LDH}$ does not play a physiological role; except perhaps during fast transitions in energy metabolism. Aging 3, 457-460.

Rajendran, P., Williams, D. E., Ho, E., and Dashwood, R. H. (2011). Metabolism as a key to histone deacetylase inhibition. Crit. Rev. Biochem. Mol. Biol. 46, 181-199.

Ramírez, B. G., Rodrigues, T. B., Violante, I. R., Cruz, F., Fonseca, L. L., Ballesteros, P., Castro, M. M., García-Martín, M. L., and Cerdán, S. (2007). Kinetic properties of the redox switch/redox coupling mechanism as determined in primary cultures of cortical neurons and astrocytes from rat brain. $J$. Neurosci. Res. 85, 3244-3253.

Rasmussen, P., Nielsen, J., Overgaard, M., Krogh-Madsen, R., Gjedde, A., Secher, N. H., and Petersen, N. C. (2010). Reduced muscle activation during exercise related to brain oxygenation and metabolism in humans. J. Physiol. 58, 1985-1995.

Rodrigues, T. B., López-Larrubia, P., and Cerdán, S. (2009). Redox dependence and compartmentation of [13C]pyruvate in the brain of deuterated rats bearing implanted C6 gliomas. J. Neurochem. 109, 237-245. Rooney, K., and Trayhurn, P. (2011). Lactate and the GPR81 receptor in metabolic regulation: implications for adipose tissue function and fatty acid utilisation by muscle during exercise. Br. J. Nutr. 106, 1310-1316.

Ros, J., Pecinska, N., Alessandri, B., Landolt, H., and Fillenz, M. (2001). Lactate reduces glutamate-induced neurotoxicity in rat cortex. J. Neurosci. Res. 66, 790-794.

Ross, J. M. (2011). Visualization of mitochondrial respiratory function using cytochrome $\mathrm{C}$ oxidase/ succinate dehydrogenase (COX) $\mathrm{SDH}$ ) double-labeling histochemistry. J. Vis. Exp. 23, 57.

Ross, J. M., Öberg, J., Brené, S., Coppotelli, G., Terzioglu, M., Pernold, K., Goiny, M., Sitnikov, R. Kehr, J., Trifunovic, A., Larsson, N. G., Hoffer, B. J., and Olson, L. (2010). High brain lactate is a hallmark of aging and caused by a shift in the lactate dehydrogenase $\mathrm{A} / \mathrm{B}$ ratio. Proc. Natl. Acad. Sci. U.S.A. 107, 20087-20092.

Sappey-Marinier, D., Calabrese, G., Fein, G., Hugg, J. W., Biggins, C., and Weiner, M. W. (1992). Effect of photic stimulation on human visual cortex lactate and phosphates using $1 \mathrm{H}$ and $31 \mathrm{P}$ magnetic resonance spectroscopy. J. Cereb. Blood Flow Metab. 12, 584-592.

Schmalbruch, I. K., Linde, R., Paulson, O. B., and Madsen, P. L. (2002). Activation-induced resetting of cerebral metabolism and flow is abolished by beta-adrenergic blockade with propranolol. Stroke 33, 251-255.

Schurr, A., Miller, J. J., Payne, R. S., and Rigor, B. M. (1999). An increase in lactate output by brain tissue serves to meet the energy needs of glutamateactivated neurons. J. Neurosci. 19, 34-39.

Schurr, A., Payne, R. S., Miller, J. J., and Rigor, B. M. (1997). Brain lactate is an obligatory aerobic energy substrate for functional recovery after hypoxia: further in vitro validation. $J$. Neurochem. 69, 423-426. 
Schurr, A., Payne, R. S., Miller, J. J., Tseng, M. T., and Rigor, B. M. (2001). Blockade of lactate transport exacerbates delayed neuronal damage in a rat model of cerebral ischemia. Brain Res. 895, 268-272.

Smith, D., Pernet, A., Hallett, W. A., Bingham, E., Marsden, P. K., and Amiel, S. A. (2003). Lactate: a preferred fuel for human brain metabolism in vivo. J. Cereb. Blood Flow Metab. 23, 658-664.

Thangaraju, M., Carswell, K. N., Prasad, P. D., and Ganapathy, V. (2009). Colon cancer cells maintain low levels of pyruvate to avoid cell death caused by inhibition of HDAC1/HDAC3. Biochem. J. 417, 379-389.

Uehara, T., Sumiyoshi, T., Itoh, H., and Kurata, K. (2008). Lactate production and neurotransmitters; evidence from microdialysis studies. Pharmacol. Biochem. Behav. 90, 273-281.

Ugrumov, M. V. (2009). Nondopaminergic neurons partly expressing dopaminergic phenotype: distribution in the brain, development and functional significance. $J$. Chem. Neuroanat. 38, 241-256.

Vaishnavi, S. N., Vlassenko, A. G., Rundle, M. M., Snyder, A. Z., Mintun, M. A., and Raichle, M. E. (2010). Regional aerobic glycolysis in the human brain. Proc. Natl. Acad. Sci. U.S.A. 107, 17757-17762.

van Hall, G. (2010). Lactate kinetics in human tissues at rest and during exercise Acta. Physiol. 199, 499-508.

Wilson, J. E. (2003). Isozymes of mammalian hexokinase: structure, subcellular localization and metabolic function. J. Exp. Biol. 206(Pt. 12), 2049-2057.

Wyss, M. T., Jolivet, R., Buck, A., Magistretti, P. J., and Weber, B. (2011). In vivo evidence for lactate as a neuronal energy source. J. Neurosci. 31, 7477-7485.

Xu, Y., Ola, M. S., Berkich, D. A., Gardner, T. W., Barber, A. J., Palmieri, F., Hutson, S. M., and LaNoue, K. F. (2007). Energy sources for glutamate neurotransmission in the retina: absence of the aspartate/glutamate carrier produces reliance on glycolysis in glia. J. Neurochem. 101, 120-131.

Conflict of Interest Statement: The authors declare that the research was conducted in the absence of any commercial or financial relationships that could be construed as a potential conflict of interest.

Received: 14 January 2012; accepted: 01 March 2012; published online: 19 March 2012.

Citation: Bergersen LH and Gjedde A (2012) Is lactate a volume transmitter of metabolic states of the brain? Front. Front. Neuroenerg. 4:5. doi: 10.3389/ fnene.2012.00005

Copyright (C) 2012 Bergersen and Gjedde. This is an open-access article distributed under the terms of the Creative Commons Attribution Non Commercial License, which permits non-commercial use, distribution, and reproduction in other forums, provided the original authors and source are credited. 